\title{
INFLUENCE OF LUTING AGENTS ON TIME REQUIRED FOR CAST POST REMOVAL BY ULTRASOUND: AN IN VITRO STUDY
}

\author{
Janir Alves SOARES ${ }^{1}$, Manoel BRITO-JÚNIOR ${ }^{2}$, Dimitri Ribas FONSECA ${ }^{3}$, Anielo Faleiro MELO ${ }^{4}$, \\ Suelleng Maria Cunha SANTOS ${ }^{5}$, Nadia Del Carmen Soto SOTOMAYOR ${ }^{6}$, Neilor Mateus Antunes BRAGA7, \\ André Luis FARIA e SILVA ${ }^{8}$
}

\author{
1- DDS, MSc, PhD, Chairman, Discipline of Endodontics, Department of Dentistry, Federal University of Valleys of Jequitinhonha and Mucuri, \\ Diamantina, $M G$, Brazil. \\ 2- DDS, MSc, Professor of Endodontics, Department of Dentistry, State University of Montes Claros; and Dental School, United Universities of the \\ North of Minas, Montes Claros, MG, Brazil. \\ 3- DDS, Professor of Prosthodontics, Federal University of Valleys of Jequitinhonha and Mucuri, Diamantina, MG, Brazil. \\ 4- DDS, Graduate Student, Federal University of Valleys of Jequitinhonha and Mucuri, Diamantina, MG, Brazil. \\ 5- DDS, MSc in Health Sciences,State University of Montes Claros, MG, Brazil. \\ 6- DDS, Graduate Student, Federal University of Valleys of Jequitinhonha and Mucuri, Diamantina, MG, Brazil. \\ 7- DDS, MSc, Professor of Endodontics, Dental School. United Universities of the North of Minas, Montes Claros, MG, Brazil. \\ 8- DDS, MSc, PhD, Professor of Integrated Clinic, Department of Dentistry, State University of Montes Claros.
}

Corresponding address: Prof. Dr. Manoel Brito Júnior - Rua Boa Vontade 227 - Santa Rita - 39400-415 - Montes Claros, MG, Brazil

Phone/Fax: +55-38-3213-3342 - e-mail: manoelbritojr@gmail.com

Received: March 6, 2008 - Accepted: 10 November, 2008

\begin{abstract}
bjective: This in vitro study evaluated the influence of luting agents on ultrasonic vibration time for intraradicular cast post removal. Material and Methods: After endodontic treatment, 30 roots of extracted human canines were embedded in resin cylinders. The post-holes were prepared at $10 \mathrm{~mm}$ depth and their impressions were taken using autopolymerizing acrylic resin. After casting procedures using a nickel-chromium alloy, the posts were randomly distributed into 3 groups $(\mathrm{n}=10)$ according to the luting material: G1- zinc phosphate (SS White) (control group), G2 - glass ionomer cement (Vidrion C; SS White), and G3- resin cement (C\&B; Bisco). In G3, the adhesive procedure was performed before post cementation. After $24 \mathrm{~h}$, the cement line was removed at the post/ tooth interface using a fine diamond bur, and the ST-09 tip of an Enac ultrasound unit was applied at maximum power on all surfaces surrounding the posts. The application time was recorded with a chronometer until the post was completely dislodged and data were analyzed by ANOVA and Tukey's test $(\mathrm{p}<0.05)$. Results: The roots were removed from the acrylic resin and inspected to detect cracks and/or fractures. The means for G1, G2, and G3 were 168.5, 59.5, and $285 \mathrm{~s}$, respectively, with statistically significant differences among them. Two G3 posts resisted removal, one of which developed a vertical fracture line. Conclusions: Therefore, the cement type had a direct influence on the time required for ultrasonic post removal. Compared to the zinc phosphate and glass ionomer cements, the resin cement required a longer ultrasonic vibration time.
\end{abstract}

Key words: Dental posts. Ultrasound. Endodontics.

\section{INTRODUCTION}

Intraradicular posts are commonly used to restore endodontically treated teeth when their remaining coronal tissue can no longer provide adequate support and retention for the restoration. Although the use of prefabricated posts has gained popularity because post placement is fast, and dental structures are preserved to a greater extent ${ }^{12,20,23}$, the custom cast post and core system has been used for several years to retain the restorations, presenting a high level of clinical success ${ }^{18}$. However, in some situations, mainly when the length and/or the diameter of the cast posts is unsatisfactory, or when the apical seal of the filling is inappropriate, endodontic retreatment is needed. In these situations, an atraumatic and efficient post removal is essential for optimal non-surgical endodontic management ${ }^{1}$. Many techniques were developed to facilitate post removal. Drills and extractors exert high force on the root and can result in root fractures ${ }^{3}$. Another commonly recommended technique is the use of an ultrasonic device ${ }^{1,5,9}$. Ultrasonic energy is transmitted to the post, causing cracks in the cement, thus facilitating post removal ${ }^{5,10}$.

For post removal, several factors can interfere in the ultrasonic efficiency, such as the type of luting agent, and 
this demands particular attention ${ }^{10,15}$. Zinc phosphate cement is the main material used to lute cast posts and cores with a satisfactory performance ${ }^{13,14}$. However, this cement presents low cohesive strength ${ }^{6}$. In this way, when root canals are short, excessively tapered or irregular, stronger cements may be recommended to improve post retention. Glass ionomer and resin cements present a higher cohesive strength than does zinc phosphate cement and can be recommended in these situations ${ }^{8,13}$. In addition, these luting materials provide favorable bond strength to the dentin root canal walls ${ }^{15}$. It has been demonstrated that the improvement in the mechanical properties, together with the bond strength, challenges post removal by tensile tests after the use of an ultrasonic device ${ }^{9,10}$. However, there is no consensus regarding the length of ultrasonic vibration time needed for removal of adhesively luted intraradicular cast posts. Thus, the aim of this in vitro study was to evaluate the effect of the luting agent on the time required for intraradicular cast post removal from the root canal using an ultrasonic device. The tested null hypothesis was that the different luting agents do not influence the time required to remove the cast post from the root canal.

\section{MATERIAL AND METHODS}

Thirty extracted human canines without endodontic treatment and with well-preserved coronal and radicular structures were selected from the tooth bank of the Dental School of the State University of Montes Claros, MG, Brazil. The selection criteria included: single-rooted teeth without pronounced flattening and straight roots with a single root canal. The teeth were previously examined under light at 10x magnification and those with cracks or fractures were discarded.

After coronal access, the teeth were treated endodontically according to a crown-down technique with a \#50 K-file (Dentsply/Maillefer, Ballaigues, Switzerland) as the master apical file. All enlargement procedures were followed by irrigation with $2.5 \%$ sodium hypochlorite (Biodinâmica Produtos Químicos Ltda, São Paulo, SP, Brazil). The smear layer was then removed using a 14.3\% EDTA solution ( $\mathrm{pH} 7.4$; Odahcam-Herpo Produtos Dentários, Petrópolis, RJ, Brazil) for 3 min and a subsequent irrigation with sodium hypochlorite. The prepared root canals were dried with paper points and filled with guttapercha cones (Odous, Belo Horizonte, MG, Brazil) and Pulp Canal Sealer-EWT cement (Kerr Corporation, Orange, CA, USA) using the lateral condensation technique. The specimens were stored at $37^{\circ} \mathrm{C}$ and $100 \%$ humidity for 1 week.

After this period, each tooth was horizontally sectioned above the cementoenamel junction with a carborundum disc (Dentorium, New York, NY, USA) to obtain a remaining root approximately $15 \mathrm{~mm}$ long. The crowns were discarded and the roots were embedded in autopolymerizing acrylic resin cylinders (Clássico, Rio de Janeiro, RJ, Brazil) to facilitate handling. The post-holes were subsequently prepared using \#1 and \#2 Largo drills (Dentsply/Maillefer) at a depth of $10 \mathrm{~mm}$. Impressions of the prepared root canal were made with autopolymerizing acrylic resin (Duralay, Reliance Dental, Worth, IL, USA) and the posts were cast in a nickel-chromium alloy (Wironia, Bego, Bremen, Germany).

Next, the specimens were randomly divided into 3 groups $(\mathrm{n}=10)$ according to the luting material: $\mathrm{G1}$ - zinc phosphate (S.S. White Dental Products, Rio de Janeiro, RJ, Brazil) (control group), G2 - glass ionomer cement (Vidrion C; S.S. White Dental Products), and G3 - autopolymerizing resin cement (C\&B; Bisco Dental Products, Inc., Itasca, IL, USA). All posts were cemented following the manufacturers' instructions. In G1 and G2 the mixed cement was inserted in the post-holes with a lentulo spiral (Dentsply/Maillefer), and the post was covered with the same cement and inserted into the root canal. In G3, the dentin walls of the root canal were etched with $32 \%$ phosphoric acid (Bisco Dental Products, Inc.) for $30 \mathrm{~s}$, rinsed with water and gently airdried. Excess water was removed from the post-hole with absorbent paper points. Two coats of the adhesive One-Step Plus (Bisco Dental Products, Inc.) were applied. The air spread was applied for $20 \mathrm{~s}$ and the adhesive was lightpolymerized (Optilight Plus, Gnatus, Ribeirão Preto, SP, Brazil) for $30 \mathrm{~s}$. The resin cement was applied as described for G1 and G2. Excess cement was removed with cotton, and the core was maintained under constant finger pressure for $1 \mathrm{~min}$. The teeth were stored at $37^{\circ} \mathrm{C}$ and $100 \%$ humidity for at least $24 \mathrm{~h}$ before testing.

The specimens were fixed to a vice for the post removal procedures. The cores were abraded with \# 1557 burs (S.S. White Dental Products) and \# 3203 tapered diamond burs (KG Sorensen, Rio de Janeiro, RJ, Brazil) at high speed, cutting an estimated $2.0 \mathrm{~mm}$ gutter around the post (Figure $1 \mathrm{~A}$ and 1B). An ultrasound device (Enac, Osada Electric Co Ltd., Tokyo, Japan) with an ST 09 tip (Osada Electric Co. Ltd., Tokyo, Japan) was used at maximum power under water cooling by a single calibrated operator. Vibration was

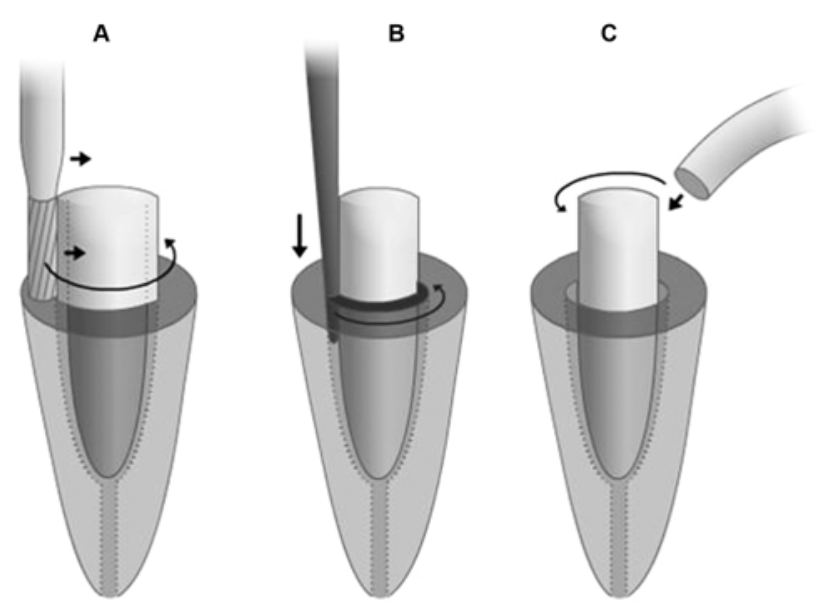

FIGURE 1- Procedures for intraradicular cast post removal. 1A- wear of the core using the \#1557 bur; 1B- wear of the cement line (2 mm depth) using the \# 3203 diamond bur; 1C- application of the ultrasound tip in all core surfaces 
TABLE 1- Mean times and standard deviations, in seconds, required for post removal

\begin{tabular}{cccc}
\hline Group & $\mathbf{n}$ & Mean* & Standard Deviation \\
\hline 1-Zinc phosphate cement & 10 & $168.56 \mathrm{a}$ & 23.53 \\
2-Glass ionomer cement & 10 & $59.57 \mathrm{~b}$ & 31.23 \\
3-Resin Cement & 10 & $285.25 \mathrm{c}$ & 45.06 \\
\hline
\end{tabular}

* Means followed by different letters are statistically different (Tukey test, $p<0.05$ ).

applied successively to the buccal, mesial, lingual, distal and incisal surfaces (Figure 1C).

The time required to completely dislodge each post was recorded with a digital progressive chronometer (Tecnbrás Indústria e Comércio Ltda, São Paulo, SP, Brazil). The values obtained were analyzed by ANOVA and Tukey's test $(\mathrm{p}<0.05)$. The roots were removed from the acrylic resin and inspected under light and magnification to detect cracks and/or fractures.

\section{RESULTS}

Table 1 shows the mean time necessary to dislodge the intraradicular posts during ultrasonic vibration. Statistically significant differences were observed among the three groups.

The posts luted with resin cement (G3) required the longest time to be removed. In addition, two posts of G3 resisted ultrasonic removal and in one of these cases a vertical fracture line developed. G2 (glass ionomer) posts were removed more rapidly than those luted with zinc phosphate cement (G1), which presented an intermediate removal time.

\section{DISCUSSION}

In restorations of endodontically treated teeth, the use of prefabricated posts reinforced with either glass-fiber or carbon, and cemented with adhesive materials present favorable biomechanical properties, and the elasticity modulus is close to that of dentin ${ }^{16,23}$. Nevertheless, to manage extensive coronal destruction, particularly of pillar teeth of partially fixed or removable prostheses, cast metal posts are still recommended ${ }^{19}$. The use of ultrasound for post removal has been proven a valuable technique, contributing to the preservation of root integrity ${ }^{1,5,9}$. In several studies, the Enac-Osada piezoelectric ultrasound device has been used for post removal ${ }^{5,9,15}$. When an ultrasonic unit is used for post removal, the vibration is transferred to the cement line by the post. Thus, the vibration is expected to cause the cement to fracture and facilitate the post removal procedure. Instead, due to the difference in mechanical properties, several studies have reported that the type of luting agent can have an influence on the ultrasonic efficiency ${ }^{9,10,20}$. In view of the increasing number of adhesive materials being used for post cementation, two adhesive cements were evaluated in this study. Zinc phosphate cement was used as the control because it is has traditionally been indicated for metal post cementation for several years ${ }^{8,14}$.

In the present study, the type of cement had a direct influence on the time required for post removal. Thus, the null hypothesis was rejected. A recent study ${ }^{17}$ found no difference in post retention when cemented with zinc phosphate or glass ionomer cements. Another investigation ${ }^{10}$ demonstrated that ultrasonic vibration for 10 min reduces the retention of zinc phosphate and glass ionomer sealers by $39 \%$ and $33 \%$, respectively. In the present study, by using these types of cement, the cast metal posts were successfully removed by ultrasonic vibration in a short time interval (mean time up to $3 \mathrm{~min}$ ). However, the time required for posts cemented with zinc phosphate was almost three times longer.

Considering that glass ionomer cement has adhesive properties and a viscoelastic nature that is able to attenuate vibrations and absorb the ultrasonic energy transmitted to the posts ${ }^{15}$, a better performance of this cement could be expected. However, the bond strength obtained by glass ionomer cements is very low ${ }^{2}$. Thus, post retention is mainly maintained through sliding friction ${ }^{4}$, such as with zinc phosphate cements. There may be some explanations for the longer time required for removing the post luted with zinc phosphate. The glass ionomer has a higher solubility (1.25 versus 0.06$)$ than does zinc phosphate ${ }^{21}$. Furthermore, the solubility of glass ionomer solubility increases when this material is used for cementation due to the lower powerliquid ratio. Thus, the water from cooling the ultrasonic devices may more easily solubilize the glass ionomer cement and contribute to post removal. Another explanation for the results is the possible incorporation of bubbles and other defects during the insertion of the glass ionomer cement. Glass ionomer flow is low and it is difficult to manipulate, making this cement more complicated to insert.

Removal of the post cemented with resin cement required a longer ultrasonic application time than the other cements. This may be explained by the superior mechanical properties of this luting material. Despite this improvement in mechanical properties, ultrasonic vibration seems be effective in fracturing the cement line obtained with the resin cement. However, Gomes, et al. ${ }^{10}$ found no reduction in the force necessary to remove posts cemented with a resin cement after the application of ultrasonic vibration for 10 
min. To the contrary, $80 \%$ of the samples luted with resin cement were successfully removed in a mean time of approximately $5 \mathrm{~min}$ in the present study. The difference in the results may be explained by the wear of the core and cementation line with burs performed in the present study before ultrasound application.

$\mathrm{C} \& \mathrm{~B}$ autopolymerizing resin cement was used in the present study. The manufacturer of this cement recommends its use associated with the All\&Bond 2 or One-Step adhesive systems. Despite the possible incompatibility between two steps of etch\&rinse adhesives with self-polymerized resin cements $^{22}$, One-Step adhesive system was chosen because of its thinner adhesive layer ${ }^{7}$. A thicker adhesive layer may indeed hinder the complete post seal. It is also important to emphasize that the low compliance of the cavity renders it nearly impossible to accommodate resin cement polymerization shrinkage during post cementation. In addition, moisture control, adhesive application, and light curing are compromised in adhesive procedures in the root canal, and low bond strength is expected. Goracci, et al. ${ }^{11}$ demonstrated that the main factor contributing to the resistance to dislocation of the posts luted with resin cement seems to be achieved by sliding friction. Thus, adhesive systems that present a thin layer, combined with an autopolymerizing resin cement, are preferable. Considering the low bond strength and close contact between the resin cement and the dentin walls, post removal depends on the cement fracturing. Consequently, the longer removal time found for the resin cement may be explained by its better mechanical properties in comparison with the other evaluated cements ${ }^{21}$.

Another finding of this study was the occurrence of root fractures when resin cement was used for cast post fixation. One possible explanation is the tight bonding of this cement to the dentin root canal walls, mainly in the cervical third ${ }^{19}$. This bonding may transmit the ultrasonic vibration to root canal walls and contribute to their fracture. Despite the few root fractures and greater difficulty when compared to other cements, ultrasonic vibration was shown to be a safe and efficient method for facilitating the removal of posts luted with resin cements.

\section{CONCLUSION}

Within the limitations of this in vitro study, it may be concluded that the type of cement had a direct influence on the time required for intraradicular cast post removal by ultrasound. When compared to zinc phosphate and glass ionomer cements, the resin cement, required a longer ultrasonic vibration time. In addition, the majority of the posts luted with resin cement were successfully removed in a relatively short time (mean time up to $5 \mathrm{~min}$ ).

\section{ACKNOWLEDGEMENT}

We thank the Tandari dental laboratory in the city of Diamantina, MG, Brazil for the casting of the metal posts used in this study.

\section{REFERENCES}

1- Abbott PV. Incidence of root fractures and methods used for post removal. Int Endod J. 2002;35(1):63-7.

2- Bonfante G, Kaizer OB, Pegoraro LF, Valle AL. Tensile bond strength of glass fiber posts luted with different cements. Braz Oral Res. 2007;21(2):159-64.

3- Castrisos T, Abbott PV. A survey of methods used for post removal specialist endodontic practice. Int Endod J. 2002;35(2):172-80.

4- Cury AH, Goracci C, Navarro MFL, Carvalho RM, Sadek FT, Tay FR, et al. Effect of hygroscopic expansion on the push-out resistance of glass ionomer-based cements used for the luting of glass fiber posts. J Endod. 2006;32(6):537-40.

5- Dixon EB, Kaczkowski PJ, Nicholls JI, Harrington GW. Comparison of two ultrasonic instruments for post removal. J Endod. 2002;28(2):1115 .

6- Ergin S, Gemalmaz D. Retentive properties of five different luting cements on base and noble metal copings. J Prosthet Dent. 2002;88(5):4917.

7- Faria e Silva AL, Lima DA, Dias de Souza GM, Dias CT, Paulillo LA. Influence of additional adhesive application on the microtensile bond strength of adhesive systems. Oper Dent. 2006;31(5):562-8.

8- Fonseca RG, Santos Cruz CA, Adabo GL, Vaz LG. Comparison of the tensile bond strengths of cast metal crowns luted with resin cements. J Oral Rehabil. 2004;31(11):1080-4.

9- Garrido AD, Fonseca TS, Alfredo E, Silva-Sousa YT, Sousa-Neto MD. Influence of ultrasound, with and without water spray cooling, on removal of posts cemented with resin or zinc phosphate cements. J Endod. 2004;30(3):173-6.

10- Gomes AP, Kubo CH, Santos RA, Santos DR, Padilha RQ. The influence of ultrasound on the retention of cast posts cemented with different agents. Int Endod J. 2001;34(2):93-9.

11- Goracci C, Fabianelli A, Sadek FT, Papacchini F, Tay FR, Ferrari M. The contribution of friction to the dislocation resistance of bonded fiber posts. J Endod. 2005;31(8):608-12.

12- Goracci C, Grandini S, Bossu M, Bertelli E, Ferrari M. Laboratory assessment of the retentive potential of adhesive posts: a review. J Dent. 2007;35(11):827-35.

13- Habib B, von Fraunhofer JA, Driscoll CF. Comparison of two luting agents used for the retention of cast dowel and cores. J Prosthodont. 2005;14(3):164-9.

14- Hagge MS, Wong RD, Lindemuth JS. Retention strengths of five luting cements on prefabricated dowels after root canal obturation with a zinc oxide/eugenol sealer: 1 . Dowel space preparation/cementation at one week after obturation. J Prosthodont. 2002;11(3):168-75.

15- Hauman CH, Chandler NP, Purton DG. Factors influencing the removal of posts. Int Endod J. 2003;36(10):687-90. 
16- Kremeier K, Fasen L, Klaiber B, Hofmann N. Influence of endodontic post type (glass fiber, quartz fiber or gold) and luting material on pushout bond strength to dentin in vitro. Dent Mater. 2008;24(5):660-6.

17- Menani LR, Ribeiro RF, Antunes RP. Tensile bond strength of cast commercially pure titanium and cast gold-alloy posts and cores cemented with two luting agents. J Prosthet Dent. 2008;99(2):141-7.

18- Salvi GE, Siegrist Guldener BE, Amstad T, Joos A, Lang NP. Clinical evaluation of root filled teeth restored with or without post-and-core systems in a specialist practice setting. Int Endod J. 2007;40(3):209-15.

19- Santos-Filho PC, Castro CG, Silva GR, Campos RE, Soares CJ. Effects of post system and length on the strain and fracture resistance of root filled bovine teeth. Int Endod J. 2008;41(6):493-501.

20- Schwartz RS, Robbins JW. Post placement and restoration of endodontically treated teeth: a literature review. J Endod. 2004;30(5):289301 .

21- Shen C. Dental cements. In: Anusavice KJ, editor. Phillip's science of dental materials. 11th ed. Saint Louis: Saunders; 2003. p. 443-94.

22- Tay FR, Suh BI, Pashley DH, Prati C, Chuang SF, Li F. Factors contributing to the incompatibility between simplified-step adhesives and self-cured or dual-cured composites. Part II. Single-bottle, total-etch adhesive. J Adhes Dent. 2003;5(2):91-105.

23- Wiskott HW, Meyer M, Perriard J, Scherrer SS. Rotational fatigueresistance of seven post types anchored on natural teeth. Dent Mater. 2007;23(11):1412-9. 